Title:

Author(s):

Submitted to:
Polymers for Nuclear Materials Processing

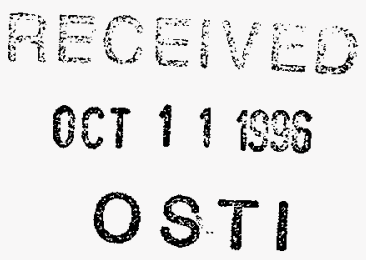

Gordon Jarvinen, NMT-6

Brian Benicewicz. MST-7

Joseph Duke, MST-7

Betty Jorgensen, MST-7

Daniel Kathios, NMT-2

Stephen Yarbro, NMT-2
DOE Office of Scientific and Technical Information (OSTI)
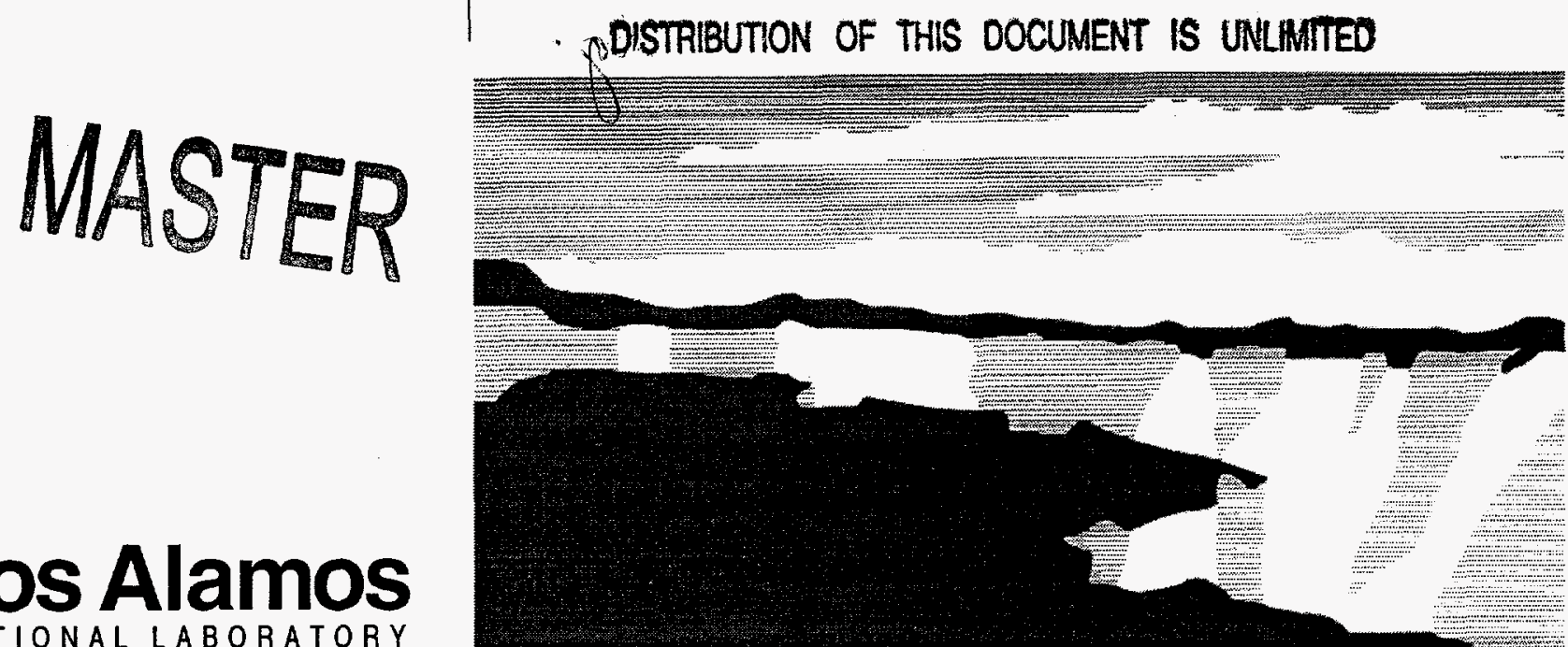

Los Alamos National Laboratory, an affirmative action/equal opportunity employer, is operated by the University of California for the U.S. Departmenl of Energy under contract W-7405-ENG-36. By acceptance of this article, the publisher recognizes that the U.S. Government retains a nonexclusive, royaltyfree license to publish or reproduce the published form of this contribution, or to allow others to do so, for U.S. Government purposes. The Los Alamos National Laboratory requests that the publisher identify this article as work performed under the auspices of the U.S. Department of Energy. 


\section{DISCLAIMER}

Portions of this document may be illegible in electronic image products. Images are produced from the best available original document. 


\section{DISCLAIMER}

This report was prepared as an account of work sponsored by an agency of the United States Government. Neither the United States Government nor any agency thereof, nor any of their employees, makes any warranty, express or implied, or assumes any legal liability or responsibility for the accuracy, completeness, or usefulness of any information, apparatus, product, or process disclosed, or represents that its use would not infringe privately owned rights. Reference herein to any specific commercial product, process, or service by trade name, trademark, manufacturer, or otherwise does not necessarily constitute or imply its endorsement, recommendation, or favoring by the United States Government or any agency thereof. The views and opinions of authors expressed herein do not necessarily state or reflect those of the United States Government or any agency thereof. 


\title{
Polymers for Nuclear Materials Processing
}

\author{
Gordon Jarvinen*, Brian Benicewicz, Joseph Duke, Betty Jorgensen, \\ Daniel Kathios, and Stephen Yarbro
}

\begin{abstract}
This is the final report of a one-year, Laboratory-Directed Research and Development (LDRD) project at the Los Alamos National Laboratory (LANL). The use of open-celled microcellular foams as solid sorbents for metal ions and other solutes could provide a revolutionary development in separation science. Macroreticular and gel-bead materials are the current state-of-the-art for solid sorbents to separate metal ions and other solutes from solution. The new polymer materials examined in this effort offer a number of advantages over the older materials that can have a large impact on industrial separations. The advantages include larger usable surface area in contact with the solution, faster sorption kinetics, ability to tailor the uniform cell size to a specific application, and elimination of channeling and packing instability.
\end{abstract}

\section{Background and Research Objectives}

Macroreticular and gel-bead materials are the current state-of-the-art for solid sorbents to separate metal ions and other solutes from solution. However, open-celled microcellular foams offer a number of advantages over these conventional sorbents that are expected to have a large impact on separations, including nuclear materials processing and waste stream cleanup. These advantages include a larger usable surface area in contact with the solution, faster sorption kinetics, the ability to tailor the uniform cell size to a specific application, and the elimination of channeling and packing instability.

\footnotetext{
* Principal investigator, e-mail: gjarvinen@lanl.gov
} 
The purpose of this project was to strengthen the development of this potentially superior separation technology by linking advanced synthetic polymer work with the experimental and theoretical tools of chemical engineering to characterize these exciting new materials and to evaluate their practical application more rapidly. To achieve this end, a variety of foams were synthesized and then engineered into a column design. Their flow properties were then evaluated over a range of air and water mobile-phase-throughput rates. These results were then compared to throughput rates expected from similar materials fabricated in resin form to validate the improvements provided by this new technology, and to a provide a basis upon which a foam can be designed and optimized to satisfy any set of process specifications.

\section{Importance to LANL's Science and Technology Base and National R\&D Needs}

The development of advanced technologies to recover radioactive species from waste streams is a major need at a number of DOE sites. Technologies are required that are faster, more efficient and produce less waste. Specific sites of the DOE complex where these new technologies are needed include Los Alamos, Rocky Flats, Idaho National Engineering Laboratory, Savannah River, and Hanford. Ion exchange and chelating resins (typically in bead form) are currently used to remove nuclear materials and other solutes from processing and waste streams. However, the bead materials have problems including packing instability, liquid channeling through the bed, slow sorption or desorption kinetics, and low usable surface areas that tend to lower their efficiencies. The use of advanced microcellular polymeric foams may help to overcome these problems. This technology may also provide a cost-effective replacement for precipitation and less efficient column extraction methods at Los Alamos and other DOE sites that are required to meet progressively more stringent discharge requirements. At Los Alamos, we are working to save millions of dollars in capital and operating costs for renovations to the Waste Treatment Facility by using improved extraction technologies that greatly reduce the transuranic content of waste streams from the Plutonium Facility. The polymer-foam technology is an advanced extraction technology that can contribute substantially to accomplishing that goal.

\section{Scientific Approach and Results to Date}

The microcellular polymer foams used in this study were fabricated using a technique originally developed at Los Alamos [1-6]. This technique uses a high-internal-phase water-inoil emulsion (HIPE) polymerization process based on modified cross linked polystyrenes and 
co-monomers. In this process, an emulsion is created in which the water is the internal phase and comprises at least $75 \%$ by volume of the emulsion and the water insoluble monomers comprise the remaining emulsion volume in the continuous oil phase. Free radical polymerization of the monomers in the emulsion state followed by removal of the water leads to the formation of a polymeric cellular material with cell sizes equivalent to the size of the water droplets in the emulsion. The large volume of water as the internal phase of the emulsion allows achieving homogeneous ultra-low density polymeric foams with densities as low as 1 $\mathrm{lb} / \mathrm{ft}^{3}$ and as high as $20 \mathrm{lb} / \mathrm{ft}^{3}$. The choice of monomers used in the oil phase allows for the post-functionalization of the foams to chelating or ion exchange materials.

In this work, foams prepared from styrene and chloromethylstyrene monomers, cross linked with divinylbenzene, were functionalized with phosphonate diacid and ester groups. Phosphonate ligands are highly efficient in taking up actinides, but for these studies, iron and europium were used as surrogates for plutonium and trivalent actinides, respectively. Foams outperformed beads of similar composition in batch tests in terms of rate of metal ion uptake and capacity from acid solutions [7]. Trivalent lanthanides such as europium are difficult to extract, but a distribution coefficient of 46.8 for $2.5 \%$ cross-linked foams was obtained in 30 minutes, compared to 9.4 for $2 \%$ cross-linked beads. For iron, the distribution coefficient was 1904 for the foam and 131 for beads with the same degrees of cross linking as above. These results show that the accessibility of the ligands in the foam is excellent.

Polymer foams were also prepared by graft polymerizing vinylpyridine to the chloromethyl group; thus, creating chains of an ion exchange polymer that resembles the resin presently used to recover plutonium at the Los Alamos Plutonium Facility. Under acidic conditions, short chains of polyvinylpyridine become water soluble due to protonation of the nitrogen. As a result, water-soluble chains are created that are grafted to a solid support. These chains are expected to provide the improved kinetics of water-soluble chelators while maintaining the benefits of solid sorbents. Testing of these materials awaits further funding. The functionalization of the foams is shown in Figure 1.

The open-celled microcellular polymeric foams can be fabricated with very specific porosities (i.e., total pore volume per unit volume of foam) and pore sizes. Maximizing the porosity and minimizing the pore size increases the surface area per unit volume of foam. This is beneficial for separation processes in that it also maximizes the number of sites in the column where either surface complexation or ion exchange or adsorption can take place. However, smaller pore sizes cause greater pressure drops to exist in the column, and higher porosities result in thinner intercellular walls with reduced structural integrity. At elevated flow rates, this may cause a longitudinal compression of the column material resulting in porosity reduction, pressure buildup or perhaps even a structural failure of the foam monolith. The design of the 
foam must therefore strike an optimum balance between maximizing its effective surface area while still maintaining its structural integrity during normal process operations. Experiments conducted in this research provided the first evaluation of the fluid-flow characteristics through these microcellular polymeric foams. Both untreated and sulfonated styrene/divinylbenzene microcellular foam cylinders were fabricated with a pore size range of $50-100 \mu \mathrm{m}$ and a porosity of over $93 \%$. These cylinders were fixed in a glass column using a styrene-based cross linking resin to seal the annular region between the foam and the glass wall. Fluid was then passed through these columns using an experimental setup (shown in Figure 2) specifically designed and constructed for this analysis. Both air and water were used as test fluids. The foams were found to have fluid flow resistances comparable to a column containing $300 \mu \mathrm{m}$ diameter resin beads. Thus, the foams not only proved to allow for superior ligand accessibility, but also allowed for relatively high mobile phase fluid throughput rates - another sign that the foams may significantly outperform conventional resin-based technologies. Each foam column in this test also successfully withstood pressure differentials of over $80 \mathrm{psi} / \mathrm{ft}$ with no sign of foam compression or structural failure.

The pores in a microcellular foam are comprised of two parts-pore voids and pore throats. The pore voids are the bubble-like volumes that account for most of the surface area in the foam. The pore throats are the small channels that connect a given pore void to one or more of its neighboring voids. In designing a foam, it is important that an adequate number of pore throats are available to provide uniform flow distribution through the column. This ensures that the dead volume (i.e., the portion of the foam that is inaccessible to fluid) is minimized, and that the surface area available for complexation or ion exchange is used as fully as possible. A large number of pore throats is also apt to form a network of pore voids that is more interconnected. Such a network is less sensitive to the occasional closure of a pore throat (from polymer swelling, column compression, fouling, etc.) due to the fact that the fluid can easily reroute itself via a different throat. In this research, a computer simulation percolation model was developed to characterize the flow distribution through a microcellular foam and to determine the degree to which foam surface area was made inaccessible due to random pore closures. The results showed that the high degree of pore size uniformity and high level of interpore connectivity (verified by scanning electron microscopy) allowed for highly uniform flow to occur through the foam that would not be adversely affected by occasional pore closures. 


\section{References}

1. Williams, Joel M., Jr., Alice M. Nyitray, and Mark H. Wilkerson, "Composite Foams," United States Patent 4,966,919, Oct. 30, 1990.

2. Williams, Joel M., Jr., Alice M. Nyitray, and Mark H. Wilkerson, "Composite Foams," United States Patent 5,037,859 Aug. 6, 1991.

3. Williams, Joel M., Jr., A. James Gray, and Mark H. Wilkerson, "Emulsion Stability and Rigid Foams from Styrene or Divinylbenzene Water-in-Oil Emulsions, "Langmuir, 6, 437-444 (1990).

4. Williams, Joel M., Jr., "High Internal Phase Water-in-Oil Emulsions: Influence of Surfactants and Cosurfactants on Emulsion Stability and Foam Quality," Langmuir, 7, 1370-1377 (1991).

5. Williams, Joel M., Jr., and Debra Wrobleski, "Spacial Distribution of the Phases in Water-in-Oil Emulsions. Open and Closed Microcellular Foam from Cross-Linked Polystyrene," Langmuir, 4, 656-662 (1988).

6. Williams, Joel M., Jr., "Toroidal Microstructures from Water-in-Oil Emulsions," Langmuir, 4, 44-49 (1988).

7. S.D. Alexandratos, R. Beauvais, J.R. Duke, Jr., and B.S., "Synthesis and Characterization of Functionalized Polymer Foam for Actinide Recovery," ; 209th American Chemical Society National Meeting, Anaheim, CA, Symposium on Ion Exchange for Lanthanide/Actinide Separations, Division of Industrial and Engineering Chemistry, April 2-7, 1995. 


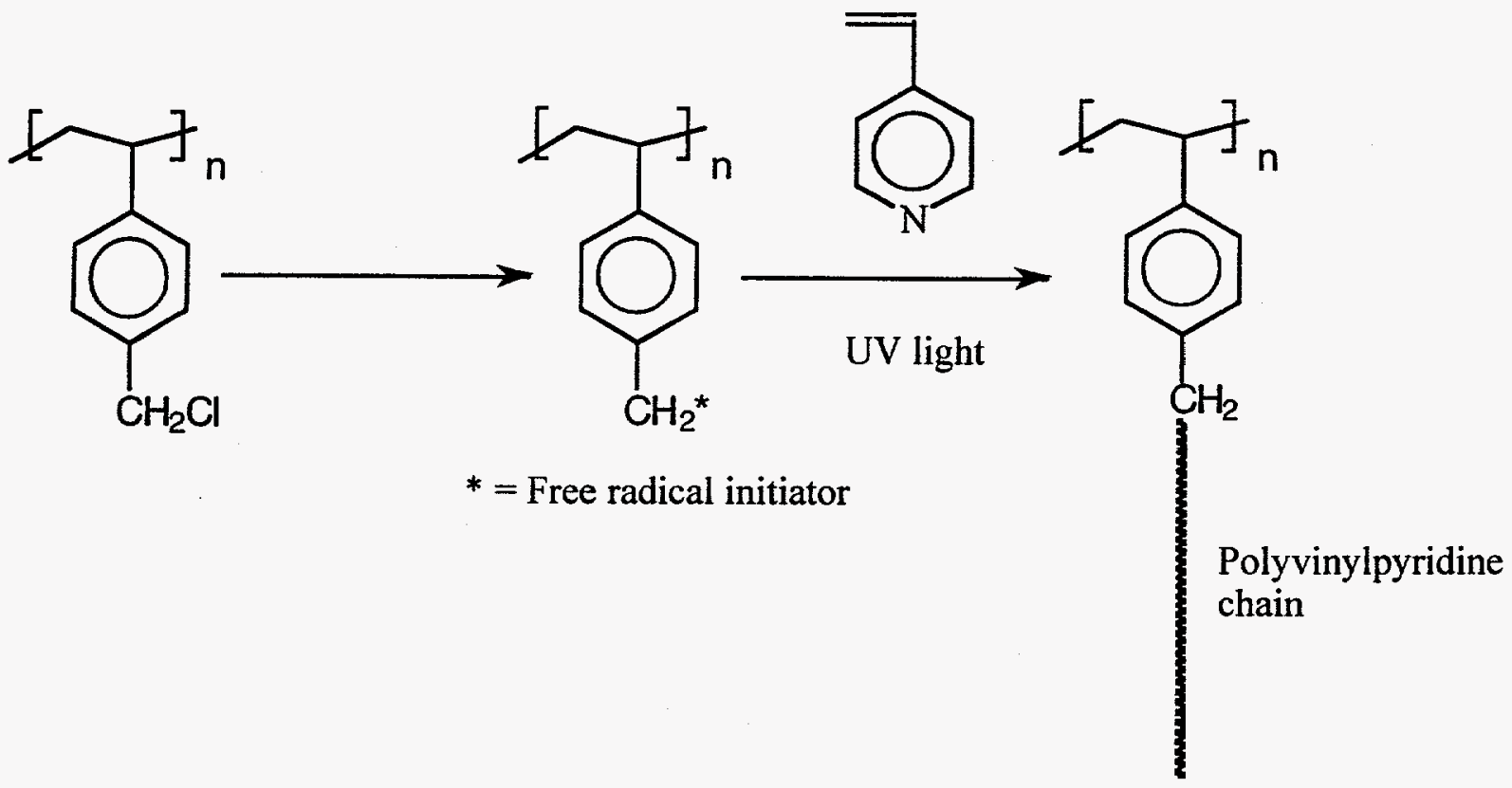

Figure 1. Reaction diagram illustrating the molecular structure of the foams and how they were functionalized. 


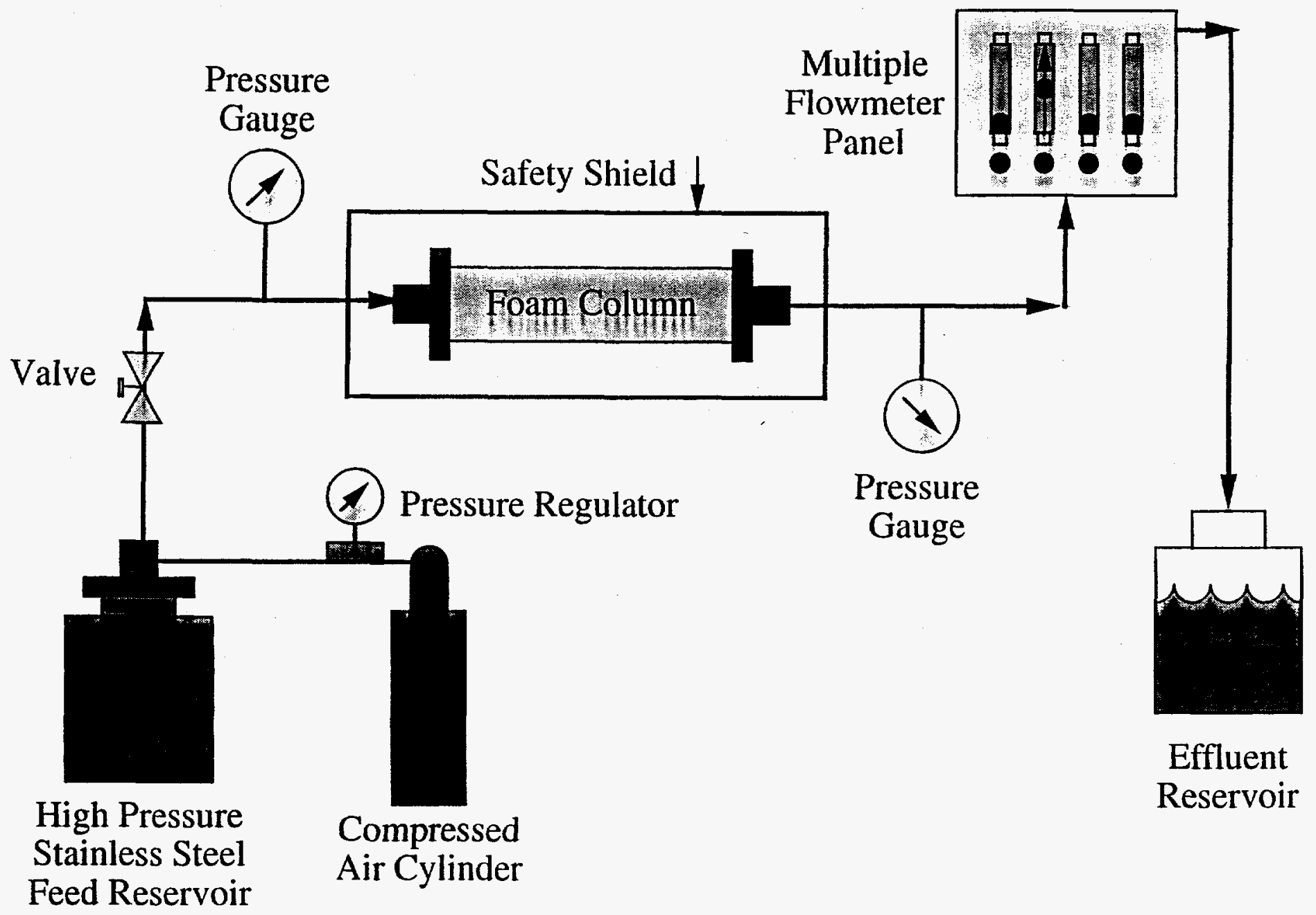

Figure 2. Experimental setup used to measure the fluid flow characteristics of air and water through the foams. 